\title{
Interstitial collagen turnover during airway remodeling in acute and chronic experimental asthma
}

\author{
GEORGINA GONZÁLEZ-AVILA ${ }^{1}$, BLANCA BAZAN-PERKINS ${ }^{2}$, CUAUHTÉMOC SANDOVAL ${ }^{1}$, \\ BETTINA SOMMER ${ }^{2}$, SEBASTIAN VADILLO-GONZALEZ ${ }^{1}$, CARLOS RAMOS $^{3}$ and ARNOLDO AQUINO-GALVEZ ${ }^{1}$ \\ ${ }^{1}$ Biomedical Oncology Laboratory, Department of Chronic-Degenerative Diseases; Departments of ${ }^{2}$ Bronchial Hiperreactivity \\ and ${ }^{3}$ Lung Fibrosis, National Institute of Respiratory Diseases 'Ismael Cosio Villegas', CP 14080 México City, Mexico
}

Received December 15, 2015; Accepted May 19, 2016

DOI: 10.3892/etm.2016.3509

\begin{abstract}
Asthma airway remodeling is characterized by the thickening of the basement membrane (BM) due to an increase in extracellular matrix (ECM) deposition, which contributes to the irreversibility of airflow obstruction. Interstitial collagens are the primary ECM components to be increased during the fibrotic process. The aim of the present study was to examine the interstitial collagen turnover during the course of acute and chronic asthma, and 1 month after the last exposure to the allergen. Guinea pigs sensitized to ovalbumin (OVA) and exposed to 3 further OVA challenges (acute model) or 12 OVA challenges (chronic model) were used as asthma experimental models. A group of animals from either model was sacrificed $1 \mathrm{~h}$ or 1 month after the last OVA challenge. Collagen distribution, collagen content, interstitial collagenase activity and matrix metalloproteinase (MMP)-1, MMP-13 and tissue inhibitor of metalloproteinase (TIMP)-1 protein expression levels were measured in the lung tissue samples from both experimental models. The results revealed that collagen deposit in bronchiole BM, adventitial and airway smooth muscle layers was increased in both experimental models as well as lung tissue collagen concentration. These structural changes persisted 1 month after the last OVA challenge. In the acute model, a decrease in collagenase activity and in MMP-1 concentration was observed. Collagenase activity returned to basal levels, and an increase in MMP-1 and MMP-13 expression levels along with a decrease in TIMP-1 expression levels were observed in animals sacrificed 1 month after the last OVA challenge. In the chronic model, there were no changes in collagenase activity or in MMP-13 concentration, although MMP-1 expression levels
\end{abstract}

Correspondence to: Dr Georgina González-Avila, Biomedical Oncology Laboratory, Department of Chronic-Degenerative Diseases, National Institute of Respiratory Diseases 'Ismael Cosio Villegas', Calzada de Tlalpan 4502, CP 14080 México City, Mexico E-mail: ggonzalezavila@yahoo.com

Key words: airway remodeling, asthma, collagen, collagenase activity, matrix metalloproteinase-1, matrix metalloproteinase-13, tissue inhibitor of metalloproteinase-1 increased. One month later, an increase in collagenase activity was observed, although MMP-1 and TIMP-1 levels were not altered. The results of the present study suggest that even when the allergen challenges were discontinued, and collagenase activity and MMP-1 expression increased, fibrosis remained, contributing to the irreversibility of bronchoconstriction.

\section{Introduction}

Asthma has been defined as a chronic airway inflammatory disease, characterized by recurrent episodes of wheezing, coughing, breathlessness and chest tightness secondary to airway bronchoconstriction (1-3). Even if asthma symptoms can be reversed with the administration of corticosteroids and bronchodilators, novel strategies for asthma control are required (4). Persistent airway obstruction is frequently observed even in asymptomatic subjects $(5,6)$. The irreversible airway obstruction is largely caused by prolonged airway inflammation associated with airway remodeling (7-9). Epithelial cell injury has been associated with a dysregulated repair process, characterized by a low proliferative rate of the epithelium that in turn produces the continuous release of growth factors and pro-fibrotic mediators (10). Under the effects of these molecules, fibroblasts and myofibroblasts increase the synthesis and deposition of extracellular matrix (ECM) components beneath the epithelium (10).

Thickening of the basal membrane (BM) lamina reticularis due to an increase of type I and type III collagens and non-collagenous proteins such as fibronectin and tenascin has been reported as a typical feature that leads to chronic airflow obstruction (1,10-12). BM structure depends of the relative rates of synthesis and degradation of ECM molecules (13). In particular, breakdown is regulated by matrix metalloproteinases (MMPs), a group of calcium-zinc-dependent endopeptidases that modify the majority of the ECM components (14). MMPs are synthesized as secreted or transmembrane zymogens and require proteolytic cleavage of the amino-terminal domain for their activation (15). According to their substrate specificity, MMPs are divided into interstitial collagenases, gelatinases, stromelysins and membrane type MMPs $(14,16)$. MMP activity is regulated by specific inhibitors, the tissue inhibitors of metalloproteinases (TIMPs) (17). TIMPs are a group of 4 proteins: TIMP-1, a $28-\mathrm{kDa}$ soluble 
protein, TIMP-2, a 21-kDa soluble/cell surface protein, TIMP-3, a 21-kDa insoluble protein bound to the ECM, and TIMP-4, a soluble/cell surface protein with a molecular weight of $24 \mathrm{kDa}(17)$.

Previous studies demonstrated that among the MMPs, MMP-9 has an important role in airway remodeling due to its ability to degrade type IV collagen, the primary component of BM, and due to its participation in the angiogenesis process $(18,19)$. Therefore, MMP-9 has been extensively studied in asthma, particularly in the pathogenesis of airway remodeling (20-22). Similarly, chronic airway inflammation and continuous collagen IV degradation lead to an abnormal deposit of interstitial collagens that are degraded by other MMPs such as MMP-1 and MMP-13 (interstitial collagenases) $(13,23,24)$. There have been previous studies on the role of MMP-1 in asthmatic airway remodeling, but none on MMP-13 (25-28). However, despite these reports, little is known about interstitial collagen degradation during the course of airway remodeling.

The aim of the present study was to analyze interstitial collagen turnover through MMP-1 and MMP-13 protein expression and collagenase activity during the early and chronic stages of asthma using asthma experimental models in guinea pigs. The interstitial collagen metabolism was also explored 1 month after the last allergen challenge to determine any changes in the airway remodeling process.

\section{Materials and methods}

Animals. Healthy male guinea pigs (strain HsdPoc: DH) were bred in the animal facilities of the National Institute of Respiratory Diseases 'Ismael Cosío Villegas' (Mexico City, Mexico) under conventional conditions (filtered conditioned air; temperature, $21 \pm 1^{\circ} \mathrm{C} ; 12 \mathrm{~h} \mathrm{light/dark} \mathrm{cycles;} 50-70 \%$ humidity; sterilized housing), and provided with ad libitum access to Harlan ${ }^{\circledR}$ pellets $(2,040$ Harlan Teklad Guinea Pig Diet) and sterilized water. The guinea pigs (aged 1 month) were sensitized to ovalbumin (OVA) and two asthma experimental models were obtained: An acute model (35 days, $n=12$ ) and a chronic model (125 days, $n=12$ ), as described below. Animals from both experimental models were divided in 2 groups consisting of 6 guinea pigs each: Group II included animals sacrificed $1 \mathrm{~h}$ after the hyperresponsiveness determination, and group III consisted of animals sacrificed 1 month after the last OVA challenge. Guinea pigs exposed to saline solution were considered as the control groups (group $\mathrm{I}, \mathrm{n}=12$ ). All animals used for the experimental models and as control groups had the same age and a similar weight (350-400 g).

The protocol was reviewed and approved by the Science and Bioethical Research Committees of the National Institute of Respiratory Diseases 'Ismael Cosío Villegas', Mexico. All experiments were carried out following the Guiding Principles for the Care and Use of Vertebrate Animals in Research and Training published by the American Physiological Society, the Mexican National Protection Laws on Animal Protection and the General Health Law Related to Health Research (NOM-062-Z00-1999).

Sensitization procedure and study design. On the first day, guinea pigs in the experimental groups $(n=24)$ received a single intraperitoneal injection of $60 \mu \mathrm{g} / \mathrm{ml}$ OVA (Sigma-Aldrich, St. Louis, MO, USA) with aluminum hydroxide $(1 \mathrm{mg} / \mathrm{ml}$; Sigma-Aldrich) dispersed in saline solution. Sensitization was reinforced 8 days later with nebulized OVA $(3 \mathrm{mg} / \mathrm{ml}$ saline) delivered for $5 \mathrm{~min}$. Aerosols were produced by a US-1 Bennett nebulizer (Multistage Liquid Impinger; Burkard Manufacturing Co., Ltd., Rickmansworth, UK; flow, $2 \mathrm{ml} / \mathrm{min}$ ); $44 \%$ of the released mixed particles were $<4 \mu \mathrm{m}$ in size, $38 \%$ were $4-10 \mu \mathrm{m}$ and $18 \%$ were $>10 \mu \mathrm{m}$. On day 15 , sensitized animals were challenged with nebulized OVA $(1 \mathrm{mg} / \mathrm{ml}$ for $1 \mathrm{~min})$. From then on, they were challenged every 10 days with nebulized OVA $(1 \mathrm{mg} / \mathrm{ml}$ in the first challenge, and $0.5 \mathrm{mg} / \mathrm{ml}$ in the subsequent challenges, for $1 \mathrm{~min}$ ); the acute model animals ( 35 days, $n=12$ ) received 3 OVA challenges and the chronic model guinea pigs (125 days, $n=12$ ) were subjected to 12 OVA challenges (Fig. 1). Control guinea pigs $(n=12)$ with the same features as the experimental guinea pigs received saline solution instead of OVA challenges. All challenges were carried out while the guinea pig was inside a barometric plethysmograph, allowing us to record the acute bronchoobstructive response to the antigenic challenge immediately following OVA delivery, as described below.

Barometric plethysmography. Barometric plethysmography was conducted as previously described and was used to confirm the development of antigen-induced airway hyperresponsiveness in the guinea pig asthma models (29). Freely moving, un-anaesthetized animals were placed in the plethysmographic chambers (Buxco Electronics Inc., Troy, NY, USA) and dose-response curves to histamine were determined prior to and following antigen or saline challenge. In all sensitized animals, the second histamine curve was obtained once the bronchoconstriction response to the OVA challenge had subsided, as previously described (30). Bronchoconstriction induced by histamine or OVA challenge was evaluated as follows: Pressure inside the plethysmographic chamber was measured through a differential transducer connected to a preamplifier. The signal from the chamber was processed with computer-installed software (Buxco Biosystem XA v1.1; Buxco Electronics Inc.) in order to calculate several respiratory parameters, such as Penh (enhanced pause). This index was obtained with the following formula:

$$
\text { Penh }=[(\text { Te-Rt }) / \text { Rt })](\text { PEP/PIP })
$$

In the equation, Te represents the expiratory time, Rt the relaxation time, PEP the peak expiratory pressure $\left(\mathrm{cm} \mathrm{H}_{2} \mathrm{O}\right)$ and PIP the peak inspiratory pressure $\left(\mathrm{cm} \mathrm{H}_{2} \mathrm{O}\right)$. The software was adjusted to only include breaths with a tidal volume of $\geq 1 \mathrm{ml}$, with a minimal inspiratory time of $0.15 \mathrm{sec}$, maximal inspiratory time of $3 \mathrm{sec}$, and maximal difference between inspiratory and expiratory volumes of $10 \%$. After the guinea pig was placed inside the plethysmographic chamber, a 5-min baseline Penh recording was initiated 5 min later. At 1 min after OVA or saline solution administration, Penh was recorded at 5 and $10 \mathrm{~min}$, and every $15 \mathrm{~min}$ thereafter. Because Penh was calculated for each breath, the data acquisition protocol from the Buxco software was set to average values from all breaths occurring during $15 \mathrm{sec}$, and then to average these values for the last $5 \mathrm{~min}$ of each period. 
OVA-induced airway hyperresponsiveness. Airway hyperresponsiveness was evaluated in sensitized animals from the 35 and 125 days model using 2 nebulized histamine dose-response curves, practiced prior and following an OVA challenge as previously described $(31,32)$. In the guinea pig, histamine aerosol administration induces an all-or-none response (33). Non-cumulative doses of histamine were administrated $(0.01-0.1 \mathrm{mg} / \mathrm{ml})$ through nebulizations lasting $1 \mathrm{~min}$ each, and after an initial Penh baseline acquisition. The time elapsed between the histamine dose-response curves $(\sim 3 \mathrm{~h})$ avoided histamine receptor desensitization (tachyphylaxis). Each dose-response curve was ended when the Penh value obtained following the corresponding histamine dose reached 3 times its basal level. Following each histamine dose, a single Penh value was registered; this value corresponded to an average of the values measured $5 \mathrm{~min}$ immediately after the agonist nebulization. The interval between doses was $10 \mathrm{~min}$. Once Penh had returned to the initial baseline value $(<50 \%$ increment), OVA challenge was administered. The second histamine curve was performed $3 \mathrm{~h}$ after the OVA challenge.

Airway responsiveness to histamine was evaluated by means of the provocative dose $200 \%\left(\mathrm{PD}_{200}\right)$, which is the interpolated histamine dose that caused a three-fold increase of the basal Penh. To evaluate the effect of the antigenic challenge on the histamine $\mathrm{PD}_{200}$, a ratio was obtained, and each $\mathrm{PD}_{200}$ value observed following the respective OVA challenge was divided by the $\mathrm{PD}_{200}$ value obtained prior to the challenge (33). Penh values obtained for each histamine dose-response curve were fitted to a curve using appropriate software (CurveExpert 1.4; http://curveexpert.software.informer.com/).

At $1 \mathrm{~h}$ after the second histamine curve, when Penh values were $\sim 50 \%$ of the basal value, the guinea pigs were sacrificed with pentobarbital sodium (i.p. $65 \mathrm{mg} / \mathrm{kg}$; Pfizer S.A. de C.V., Toluca, Mexico). The right lung was excised and fixed by manually perfusing neutral buffered $10 \%$ formaldehyde via the intra-arterial route until the lung was exsanguinated. Lung fragments obtained by sagittal cutting were embedded in paraffin, and $4 \mu \mathrm{m}$-thick lung sections were stained with Masson's trichrome for collagen deposit identification. The left lung was prepared for collagen concentration measurement, interstitial collagenase activity assay and western blot analysis.

Collagen concentration determination. Fresh lung sections of $\sim 50 \mathrm{mg}$ wet weight were dried at constant heat $\left(100^{\circ} \mathrm{C}\right)$ until all reached approximately the same dry weight $(30 \mathrm{mg})$, and the lung tissue was then hydrolyzed in $6 \mathrm{~N} \mathrm{HCl}$ at $100^{\circ} \mathrm{C}$ in a vacuum for $24 \mathrm{~h}$, prior to being evaporated. Hydroxyproline content was measured as previously described by Rojkind et al (34). The amount of collagen in each sample was calculated by multiplying the hydroxyproline content value by 7.42 on the assumption that this residue constitutes $\sim 14 \%$ of the total amount of amino acids in the $\alpha$-chain. Collagen concentration was expressed in milligrams of collagen per gram of dry lung tissue.

Interstitial collagenase activity assay. Sections of normal and experimental lung tissue $(0.5 \mathrm{~g} / \mathrm{ml})$ were suspended in $0.1 \mathrm{mM}$ Tris-HCl buffer, $\mathrm{pH} 7.8$, with $0.15 \mathrm{mM} \mathrm{NaCl}$, $10 \mathrm{mM} \mathrm{CaCl}$ and $0.02 \%$ sodium azide and homogenized in a Polytron (Brinkmann Instuments, Inc., Westbury, NY, USA). Homogenates were centrifuged at 5,000 x g for

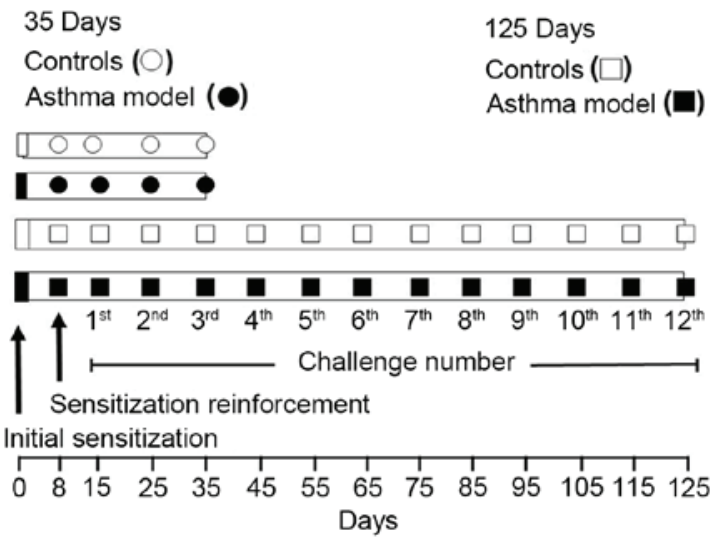

Figure 1. Experimental design. Initially, guinea pigs from both experimental models received OVA intraperitoneally. After 1 week, a sensitization reinforcement was given. The guinea pigs in both groups received a 1st OVA challenge 2 weeks (day 15) after initial intraperitoneal OVA administration. Those guinea pigs randomly assigned to the 35 days experimental model received two further OVA challenges. Each challenge was carried out 10 days apart from the other. Guinea pigs assigned to the 125 days experimental model were challenged with OVA in the same manner every 10 days for 12 weeks. Guinea pigs were sacrificed at 35 and 125 days after antigen-induced airway hyperresponsiveness was evaluated. A group of guinea pigs from the acute and from the chronic model were sacrificed 1 month after the last OVA challenge. OVA, ovalbumin.

15 min at $4^{\circ} \mathrm{C}$. Protein concentration was determined in the supernatant samples using a bicinchoninic acid protein assay (Pierce Biotechnology, Inc., Rockford, IL, USA) as previously described (35). Supernatants contained tissue-soluble proteins that were used to assay collagenase activity and western blot assays.

Interstitial collagenase activity was determined in the supernatant samples as previously described by Terato et al (36). The assay was performed incubating $20 \mu \mathrm{g}$ sample protein with $20 \mu \mathrm{g}{ }^{3} \mathrm{H}$-acetic anhydride-labeled type I collagen (GE Healthcare Life Sciences, Chalfont, UK) as a substrate (specific activity $1.6 \times 10^{6} \mathrm{dpm} / \mathrm{mg}$ ) and $50 \mathrm{mM}$ Tris- $\mathrm{HCl}, 0.15 \mathrm{mM}$ $\mathrm{NaCl}, 20 \mathrm{mM} \mathrm{CaCl}$, and $0.02 \%$ sodium azide, $\mathrm{pH} 7.4$ (TNC buffer) with or without $80 \mathrm{mM}$ EDTA (final concentration) at $30^{\circ} \mathrm{C}$ for $24 \mathrm{~h}$. Labeled collagen and clostridium collagenase (Sigma-Aldrich) and collagen with TNC buffer were used as positive and negative controls, respectively. To prevent activity of other proteases, $0.1 \mathrm{mM}$ phenylmethylsulfonylfluoride (Sigma-Aldrich) and $2.5 \mathrm{mM} \mathrm{N}$-ethylmaleimide (Sigma-Aldrich) were used. Collagenase activity was limited to EDTA-inhibitable ${ }^{3} \mathrm{H}$-collagen degradation. The results of the collagenase activity were expressed as micrograms of degraded collagen per milligram of sample incubated protein.

Western blot analysis. Western blotting was carried out using $25 \mu \mathrm{g}$ sample protein per lane in $8 \%$ SDS-PAGE gels under reducing conditions with 5\% 2-mercaptoethanol boiled for $10 \mathrm{~min}$. Following electrophoresis, the proteins were transferred to polyvinylidene fluoride membranes and blocked with $2.5 \%$ non-fat dry milk in $100 \mathrm{mM}$ Tris- $\mathrm{HCl}$ buffer, $\mathrm{pH} 7.5$ with $150 \mathrm{mM}$ $\mathrm{NaCl}$ and $0.1 \%$ Tween 20 (TTBS buffer). The membranes were incubated for $90 \mathrm{~min}$ at room temperature with the following antibodies: Mouse anti-MMP-1 (Ab-1) monoclonal antibody (1:500; cat. no. IM35; EMD Millipore, Billerica, MA, USA), 
mouse anti-MMP-13 (Ab-1) monoclonal antibody (1:500; cat. no. MAB3321; EMD Millipore), mouse anti-TIMP-1 (Ab-1) monoclonal antibody (1:500; cat. no. IM32; EMD Millipore) and rabbit anti- $\beta$-tubulin polyclonal antibody (1:250; cat. no. ab6046; Abcam, Cambridge MA, USA), which served as a loading control. Unbound antibodies were removed by washing with TTBS buffer. The primary antibodies were then detected with a VectaStain ABC kit (Vector Laboratories, Burlingame, CA, USA) according to the manufacturer's protocol. Bands detected in the western blot assay were analyzed by densitometry using Kodak Digital Science ID Image Analysis Software, version 2.0 (Kodak, Rochester, NY, USA) that measures the area and intensity of the bands. The results were expressed as densitometry units (DU).

Statistical analysis. All data are expressed as means \pm standard error. Statistical Analysis was performed using IBM SPSS 20.0 software (IBM SPSS, Armonk, NY, USA). Comparisons between the control and asthma model group hyperresponsiveness data were evaluated by means of unpaired Student's t-tests. For multiple comparisons, one way or repeated analysis of variance (ANOVA) followed by Bonferroni's test were used. Collagen concentration, collagenase activity and western blotting results were analyzed using a Kruskal-Wallis ANOVA by ranks test with a multiple comparison of mean ranks for all groups $(\mathrm{P}<0.05)$. A Mann-Whitney $\mathrm{U}$ test was used to compare results between the 35 and 125 day experimental models. $\mathrm{P}<0.05$ was considered to indicate a statistically significant difference.

\section{Results}

Antigen-induced airway obstruction and hyperresponsiveness. Basal Penh values and initial histamine curve $\mathrm{PD}_{200}$ values were similar in animals from the control and both asthma model groups (data not shown). Saline nebulization did not modify Penh basal values in control animals. OVA challenges in sensitized animals generated a reversible bronchoconstriction, defined by a transient Penh increment, which lasted $\sim 2 \mathrm{~h}$. This percentage increase in Penh values in the experimental models $(440.9 \pm 33.9 \%$ in the 35 days group and $400 \pm 30.8 \%$ in the 125 days group) was significantly higher, as compared with Penh values in the control groups (112.9 $\pm 2.9 \%$ and $130.2 \pm 6.7 \%$ in the 35 and 125 days control groups respectively; $\mathrm{P}<0.01$; Fig. 2 ).

When hyperresponsiveness to histamine was evaluated, no changes in $\mathrm{PD}_{200}$ values were observed in the saline-challenged control animals. Guinea pigs from both asthma models exhibited a significant decrease in histamine $\mathrm{PD}_{200}$ ratio as compared with the control group $(0.84 \pm 0.1 \mathrm{mg} / \mathrm{ml}$ and $0.47 \pm 0.06 \mathrm{mg} / \mathrm{ml}$ for the control and 35 day asthma model group, respectively; $\mathrm{P}=0.01$; and $1.23 \pm 0.21 \mathrm{mg} / \mathrm{ml}$ and $0.65 \pm 0.06 \mathrm{mg} / \mathrm{ml}$ for the control and 125 day asthma model group, respectively; $\mathrm{P}=0.04$; Fig. 3).

Collagen concentration. Masson's trichrome stain revealed an increase in collagen deposit (blue stain) in bronchiole BM (green arrows) and in the adventitial layers (red arrows) in guinea pigs from both experimental models (groups II; Fig. 4). Blue bands were also observed in and around airway smooth muscle (ASM) layers (blue arrows). The increase in connective

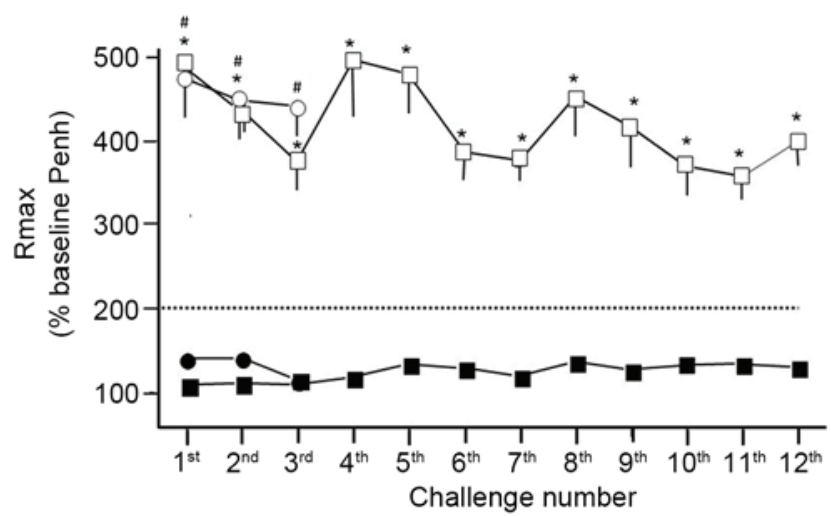

Figure 2. Airway bronchoconstriction induced by OVA challenges in sensitized guinea pigs. Bronchoconstriction induced by OVA challenges in sensitized guinea pigs was recorded and an average of maximum airway resistance Rmax (acute model white circles and chronic model white squares) was obtained. Control animals were challenged with physiological saline solution (acute model black circles and chronic model black squares). Significant differences were observed between the experimental and control groups. ${ }^{~} \mathrm{P}<0.01$ and ${ }^{*} \mathrm{P}<0.01$, vs, the respective control group. Symbols represent means \pm standard error. Penh, airway obstruction index; OVA, ovalbumin

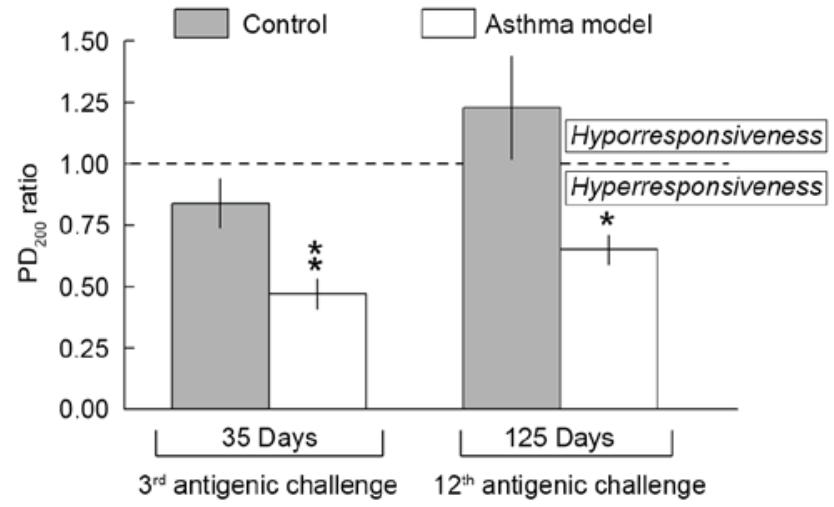

Figure 3. Airway hyperresponsiveness to histamine induced by OVA challenge in sensitized guinea pigs. Guinea pigs in both experimental models and their respective controls were administered increasing doses of nebulized histamine prior to OVA (sensitized) or saline solution (control) administration. Once the OVA-induced bronchoconstriction subsided, a second histamine dose-response curve was built. Responses to histamine are expressed as provocative dose ratio. Histamine $\mathrm{PD}_{200}$ ratio was significantly decreased in both asthma models compared with their respective control groups. The discontinuous line delimited the border between hyperresponsiveness (below the line) and hyporresponsiveness (above the line). ${ }^{* *} \mathrm{P}=0.01$ and ${ }^{*} \mathrm{P}=0.04$, vs. the respective control group. Bars represent means \pm standard error. OVA, ovalbumin; $\mathrm{PD}_{200}$, provocative dose $200 \%$.

tissue deposit was more evident in group II from the 125 days model. The increase in collagen deposit remained despite cessation of the antigen exposition in both models. Epithelial hyperplasia was observed in bronchioles from both experimental models although it was more evident in animals from the 125 days model. The bronchiole epithelial hyperplasia decreased when OVA challenges ceased in the 125 days model (group III), although it persisted in both experimental models 1 month after the last OVA challenge.

Collagen concentration was estimated by measuring hydroxyproline tissue content. There was a significant increase in collagen content in the guinea pigs in group III when compared 


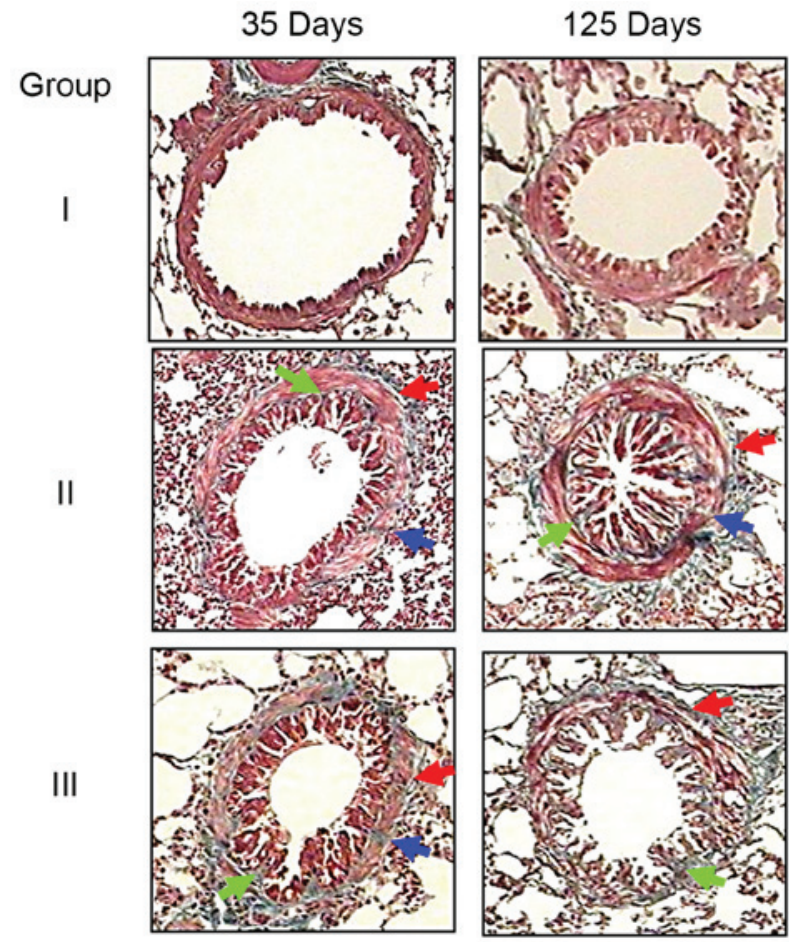

Figure 4. Guinea pig bronchiole histopathological features. Collagen fibers were increased in the bronchiole adventitial layer (red arrows), in the airway smooth muscle layer (blue arrows), and in the basement membranes (green arrows) in the tissue samples from guinea pigs of the 35 day experimental model sacrificed $1 \mathrm{~h}$ after hyperresponsiveness determination (group II). The increase in collagen fibers was more evident in bronchioles from the 125 day model (group II). Epithelial hyperplasia was also observed in bronchioles in the guinea pigs of this group. The increase in collagen deposition remained in the bronchioles 1 month after the last ovalbumin challenge (group III). Original magnification, $\mathrm{x} 40$.

with the respective control groups (group I) (35 day model, $\mathrm{P}=0.0003 ; 125$ day model, $\mathrm{P}=0.0003$; Table I). Collagen concentration was significantly higher in group III from the 125 day model compared with the 35 day model $(\mathrm{P}=0.015)$.

Interstitial collagenase activity. In the 35 day model, collagenase activity was significantly decreased in the tissue samples of group II animals $(35.1 \pm 0.8 \mu \mathrm{g}$ of degraded collagen $/ \mathrm{mg}$ of incubated protein), as compared with group I and group III samples $(72.9 \pm 6.7$ and $75.7 \pm 8.6 \mu \mathrm{g}$ of degraded collagen/mg of incubated protein, respectively; $\mathrm{P}=0.04$ and $\mathrm{P}=0.02$, respectively; Fig. 5).

Regarding the 125 day experimental model, there was a significant increase in collagenase activity in tissue samples from group III, as compared with group I $(116.9 \pm 5.7$ and $84.9 \pm 4.1 \mu \mathrm{g}$ of degraded collagen $/ \mathrm{mg}$ of incubated protein, respectively; $\mathrm{P}=0.003)$. There were no significant differences between group II and III interstitial collagenase activity.

Following comparison of group II in both models, the 125 day model exhibited a higher collagenase activity, as compared with the 35 day model $(97.8 \pm 3.6$ and $35.1 \pm 0.8 \mu \mathrm{g}$ of degraded collagen $/ \mathrm{mg}$ of incubated protein, respectively; $\mathrm{P}=0.003)$. There were also significant differences among groups III from the 35 and 125 day asthma models $(75.7 \pm 8.6$ and $116.9 \pm 5.3 \mu \mathrm{g}$ of degraded collagen $/ \mathrm{mg}$ of incubated protein, respectively; $\mathrm{P}=0.004$ ).
Table I. Collagen concentration in experimental asthma models (expressed as milligrams of collagen per gram dry lung tissue).

\begin{tabular}{lll}
\hline Group & 35 days & 125 days \\
\hline I & $38.5 \pm 1.5$ & $37.6 \pm 1.2$ \\
II & $53.1 \pm 1.9$ & $55.5 \pm 4.3$ \\
III & $73.3 \pm 2$ & $84.1 \pm 2.4$ \\
\hline
\end{tabular}

All values are expressed as mean \pm standard errors ( $n=6$ for each group).

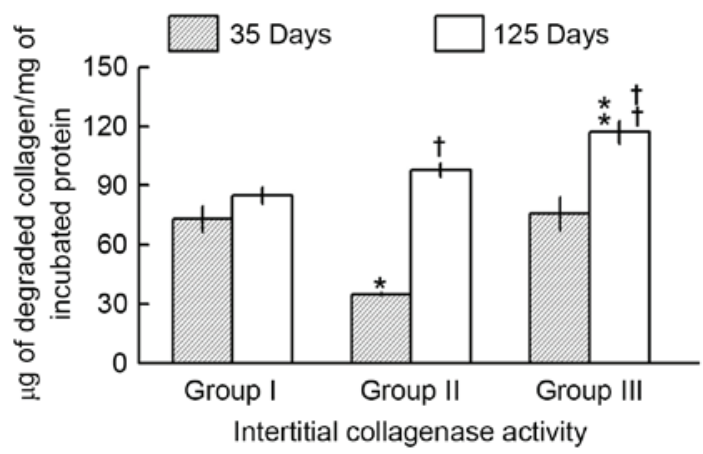

Figure 5. Interstitial collagenase activity. Lung homogenates from animals in the 35 day model group II showed a significant decrease in enzymatic activity as compared with the 35 day model groups I and III. ${ }^{*} \mathrm{P}<0.05$ vs. groups I and III. Interstitial collagenase activity was significantly higher in tissue samples from the 125 day model group III, as compared with the control group. ${ }^{* *} \mathrm{P}=0.003$, vs. group I. Enzymatic activity was significantly higher in the 125 day model groups compared with the 35 day model groups (groups II, ${ }^{\dagger} \mathrm{P}=0.003$; groups III, $\left.{ }^{\dagger} \mathrm{P}=0.004\right)$. Bars indicate means \pm standard error.

Tissue MMP-1, MMP-13 and TIMP-1 protein expression levels in the 35 day asthma model. Western blot assays revealed the presence of MMP-1 as a band of 56-kDa which corresponds to the MMP-1 active form. This band was found in tissue homogenates from guinea pigs from every one of the 3 groups in the 35 day experimental model (Fig. 6A). MMP-1 densitometry analysis demonstrated a significant decrease in MMP-1 expression levels in tissue from group II animals, as compared with tissue samples from group III $(49,325.3 \pm 3,319.9$ and 97,338.1 $\pm 1,038.1 \mathrm{DU}$, respectively; $\mathrm{P}=0.013$; Fig. 6B). There were no significant differences in MMP-1 concentration between group II and group I (76,641.7 $\pm 4,250 \mathrm{DU})$.

The MMP-13 active and latent forms $(45-$ and $60-\mathrm{kDa}$ bands) were detected in tissue samples from the control animals (group I), but only the active form was observed in the samples from groups II and III (Fig. 6A). Furthermore, active MMP-13 expression levels were significantly decreased in tissue samples belonging to group III guinea pigs $(9,756.3 \pm 749.9 \mathrm{DU})$, as compared with group I and II $(39,118.9 \pm 2,263.8$ and 57,430.4 $\pm 4,453.3$ DU, respectively; P<0.003; Fig. 6B).

TIMP-1 western blot analysis demonstrated the presence of free TIMP- 1 as a band of $28-\mathrm{kDa}$ in the 3 groups (Fig. 6A). A band of $\sim 20-\mathrm{kDa}$, which corresponds to unglycosylated TIMP-1 was observed in the tissue samples of guinea pigs in group II (37). TIMP-1 polymers likely composed of TIMP-1 complete molecules (56- and 90-kDa bands) or TIMP-1 fragments (45- and 130-kDa bands) were observed in samples 
A

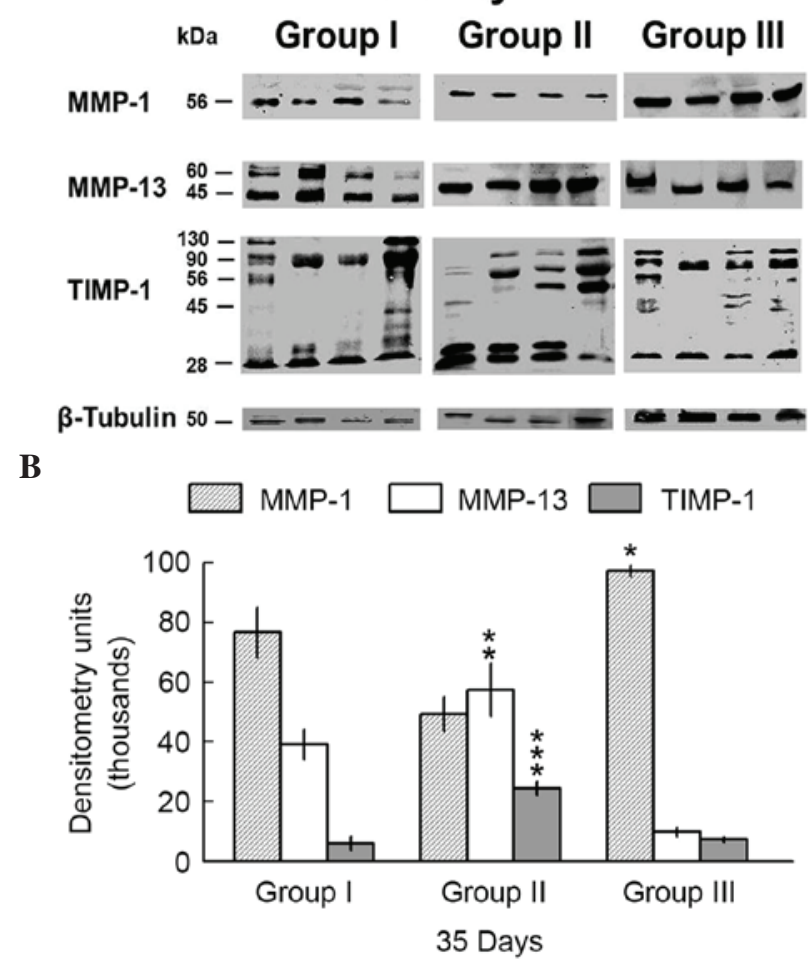

Figure 6. MMP and TIMP-1 protein expression levels in tissue samples from the 35 day asthma experimental model. (A) Active MMP-1 and MMP-13 forms were observed in all samples assayed (56- and 45-kDa bands, respectively). Pro-MMP-13 was identified in tissue samples from group II (60-kDa band). TIMP-1 was present as a $28-\mathrm{kDa}$ band in the majority of tissue samples. Bands of larger weight which correspond to TIMP-1 polymers or complexes were also observed. (B) Densitometry analysis showed a significant increase in MMP-1 expression levels in samples belonging to group III as compared with group II (" $\mathrm{P}=0.013)$. Group II MMP-13 expression levels were significantly higher, as compared with those of group III ( $\left.{ }^{* *} \mathrm{P}=0.003\right)$ TIMP-1 expression levels were significantly increased in group II, as compared with TIMP-1 expression levels in the tissue samples of control animals (group I; ${ }^{* * *} \mathrm{P}=0.01$ ). Bars represent the mean \pm standard error. MMP, matrix metalloproteinase; TIMP, tissue inhibitors of metalloproteinase.

from the 3 groups. The 90- and 130-kDa bands may also correspond to complexes between TIMP-1 with MMPs or their degradation fragments. Densitometry analysis revealed a significant increase in free TIMP-1 in group II tissue samples, as compared with the control group $(24,356 \pm 1,150.4$ and $5,893.5 \pm 1,123 \mathrm{DU}$, respectively; $\mathrm{P}=0.01$ ); this was not the case for the tissue samples obtained from group III guinea pigs (7,255.34 \pm 795.4 DU; Fig. 6B).

Tissue MMP-1, MMP-13 and TIMP-1 protein expression levels in the 125 day asthma model. Immunoblotting assay demonstrated the presence of MMP-1 as a band of $56-\mathrm{kDa}$ (active form) in the tissue samples of animals from all 3 groups (Fig. 7A). MMP-1 expression levels were significantly higher in group II tissue samples, as compared with tissue samples obtained from the control animals $(95,204.3 \pm 4,677.2$ and 48,351 $\pm 4,920.6 \mathrm{DU}$, respectively; $\mathrm{P}=0.03$ ), but not with group III tissue samples (55,058.7 55,196.5 DU; Fig. 7B).

MMP-13 western blotting showed bands of $\sim 45$ - and 60-kDa (MMP-13 active and latent forms) in almost all tissue samples from the 3 groups (Fig. 7A). The MMP-13 active
$\mathbf{A}$

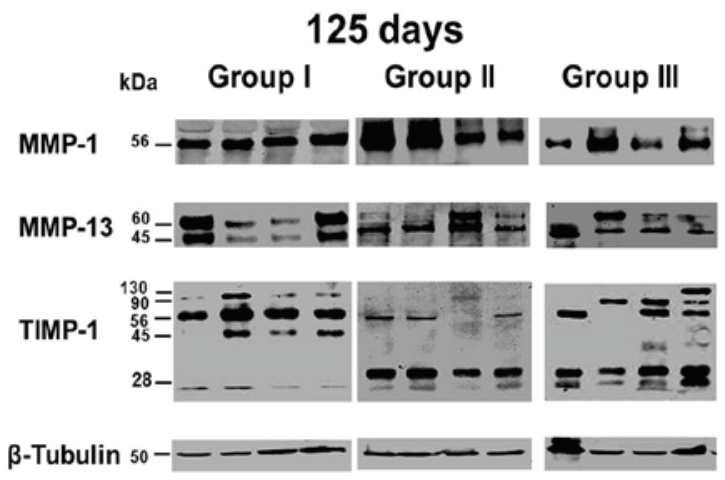

B

MMP-1

MMP-13

TIMP-1

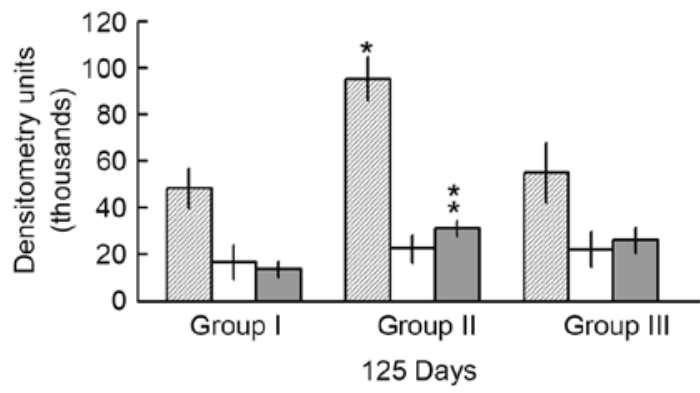

Figure 7. MMP and TIMP-1 protein expression levels in tissue samples from the 125 day asthma experimental model. (A) MMP-1 was observed as a 56-kDa band in all samples assayed. Pro-MMP-13 and MMP-13 active forms were visualized in all groups. TIMP-1 (28-kDa band) as well as TIMP-1 polymers and complexes were also identified in all samples, particularly in group III animals. (B) A significant increase in MMP-1 expression levels was observed in tissue samples from group II, as compared with control animals $\left({ }^{*} \mathrm{P}=0.03\right)$. MMP-13 expression levels were similar in tissue samples from the 3 groups. TIMP-1 protein expression levels in group II tissue samples were significantly increased, as compared with group I ( $\left.{ }^{* *} \mathrm{P}=0.02\right)$. Bars indicate the mean \pm standard error. MMP, matrix metalloproteinase; TIMP, tissue inhibitors of metalloproteinase.

form densitometry analysis revealed no significant differences among the tissue samples from the 3 groups (Fig. 7B).

Similarly to the 35 days model, TIMP-1 immunoblotting demonstrated the presence of several bands (45-, 56-, 90and $130-\mathrm{kDa}$ bands), specifically in group III tissue samples (Fig. 7A). Bands of 28-(free TIMP-1) and 20-kDa (unglycocylated TIMP-1), were also observed in the experimental asthma groups. A significant increase in TIMP-1 expression levels was observed in tissue samples from group II animals, as compared with the control group tissue samples $(31,099.5 \pm 1,740.3$ and 13,701.25 $\pm 1,744.7$ DU, respectively; P=0.02; Fig. 7B).

Comparison of MMP and TIMP-1 protein expression in both experimental asthma models. MMP-1 concentrations were significantly higher in group II from the 125 day model compared with group II from the 35 day model $(95,204.3 \pm 4,677.2$ and 49,325.3 $\pm 3,319.9$ DU, respectively; $\mathrm{P}=0.05$; Fig. 8A). There were also significant differences in MMP-1 content between group III from the 35 day model and group III from the 125 day model $(97,338.1 \pm 1,038.1$ and $55,058.7 \pm 5,196.5 \mathrm{DU}$, respectively; $\mathrm{P}=0.02)$. There were no significant differences between groups I in either model.

MMP-13 expression levels were significantly increased in the tissue samples of group I from the 35 day model, as compared 
A

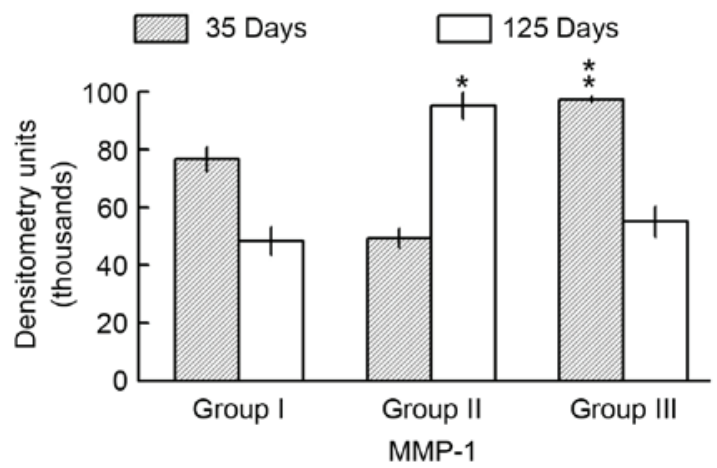

B

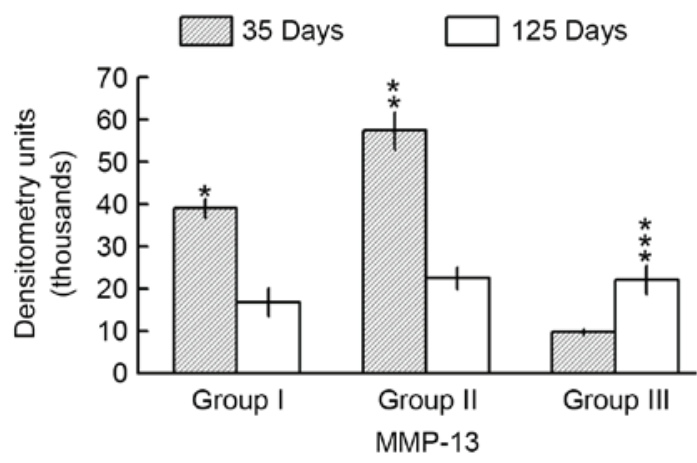

$\mathbf{C}$

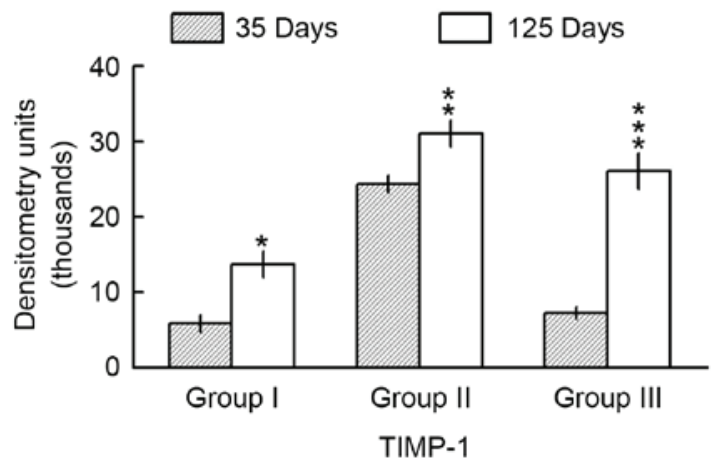

Figure 8. Comparison of MMP and TIMP-1 tissue concentrations in the acute and chronic experimental models of asthma. (A) MMP-1 levels were significantly increased in group II from the chronic model (125 days), as compared with group II from the acute model (35 days; ${ }^{*} \mathrm{P}=0.05$ ). MMP-1 levels were significantly higher in group III from the 35 days model than group III from the 125 days model $\left({ }^{* *} \mathrm{P}=0.02\right)$. (B) MMP-13 levels were significantly increased in group I and II from the acute model (35 days), as compared with the chronic model ( 125 days; ${ }^{*} \mathrm{P}=0.008$ and ${ }^{* *} \mathrm{P}=0.02$, respectively). Conversely, MMP-13 levels were significantly increased in group III from the chronic model (125 days), as compared with group III from the acute model (35 days; ${ }^{* * *} \mathrm{P}=0.02$ ). (C) TIMP-1 concentration was significantly increased in the 3 groups from the chronic model (125 days), as compared with groups from the acute model ( 35 days; ${ }^{*} \mathrm{P}=0.03,{ }^{* * *} \mathrm{P}=0.03$ and ${ }^{* * *} \mathrm{P}=0.008$ ). Bars indicate means \pm standard error. MMP, matrix metalloproteinase; TIMP, tissue inhibitors of metalloproteinase.

with group I samples from the 125 day model $(39,118.9 \pm 2,263.8$ and 16,765 $\pm 3,297.4 \mathrm{DU}$, respectively; $\mathrm{P}=0.008$; Fig. 8B). These MMP expression levels were also increased in group II from the 35 day model compared with tissue samples from the 125 day group II guinea pigs $(57,430.4 \pm 4,453.3$ and $22,488.5 \pm 2,613.3 \mathrm{DU}$, respectively; $\mathrm{P}=0.02$ ). Conversely, there was a significant decrease in MMP-13 protein expression levels in group III tissue samples from the 35 day model, as compared with tissue samples from the 125 day model $(9,756.3 \pm 749.9$ and $22,080.8 \pm 3,410.9 \mathrm{DU}$, respectively; $\mathrm{P}=0.02$ ).
TIMP-1 concentrations were significantly lower in the 3 groups from the 35 day model, as compared with the 125 day model: 35 and 125 day groups I, 5,893.5 $\pm 1,123.03$ and $13,701.3 \pm 1,744.17 \mathrm{DU}$, respectively $(\mathrm{P}=0.03) ; 35$ and 125 day groups II, 24,356 $\pm 1,150.4$ and $31,099.5 \pm 1,740.3 \mathrm{DU}$, respectively $(\mathrm{P}=0.03)$; and 35 and 125 day groups III, 7,255.3 \pm 795.4 and 26,103.8 $\pm 2,380.7 \mathrm{DU}$, respectively ( $\mathrm{P}=0.008$; Fig. $8 \mathrm{C})$.

\section{Discussion}

The present study explored how collagen metabolism changes in airway tissues from guinea pigs subjected to an acute (35 days) or a chronic (125 days) experimental model of atopic asthma. In histological samples stained with Masson's trichrome, an increase in the deposit of collagen in the subepithelial and adventitia layers, around the bronchioles and among smooth muscle fibers was observed, and these changes were more evident in the 125 day experimental model. An increase in collagen concentration was observed in lung tissue samples obtained from those animals that were sacrificed 1 month after the last OVA-challenge, particularly in the 125 days model. Using immunohistochemical techniques or by measuring HO-proline in lung homogenates from guinea pig chronic models, previous studies also demonstrated an increase in collagen deposition $(33,38,39)$. However, data on interstitial collagen increase in human airway walls remains controversial. Previous studies have demonstrated an increase in collagens type I and III underlying the airway epithelium, whereas other reports suggested that the reticular BM thickening was not due to an abnormal deposition of interstitial collagens (11,40-44).

Regarding ECM degradation, interstitial collagenase activity was decreased in animals that received the third OVA challenge (35 day model). This is consistent with the increase in collagen concentration observed in the tissue from these animals. One month later, the enzymatic activity returned to basal values, although the collagen deposit remained increased. This pattern in the enzymatic activity is similar to the one observed in MMP-1 expression, rather than to changes in MMP-13 synthesis. Similarly, the increase in TIMP-1 quantities contributes to the decrease of collagenase activity in this group of animals. Conversely, a decrease in TIMP-1 expression levels may be associated with the increase in collagenase activity observed 1 month later in the tissue samples of this experimental model. Notably, in the current study not only free TIMP-1 was detected (28-kDa band) but also several other bands that correspond to TIMP-1 polymers and TIMP-1 complexes with MMP degradation fragments. In addition to the inhibition of MMP enzymatic activity, TIMP-1 has other functions such as the activation of pro-MMP-9 through the formation of the pro-MMP-9/MMP-3/TIMP-1 activation complex (130-kDa band) (45). MMP-9 has an important role in the pathogenesis of asthma airway remodeling, therefore it was not surprising to observe increased levels of TIMP-1 as well as pro-MMP-9 activation complexes in the experimental models $(46,47)$.

Collagen metabolism was different in the chronic experimental model due to the number of OVA challenges and/or due to the differences in the age of the animals. First, collagenase activity did not change during OVA treatment (12 OVA 
challenges) with a little but significant increase 1 month after the last OVA challenge. However, this increase in collagenase activity was not sufficient to prevent collagen deposition. In this context, it has been reported that decorin, a small leucine-rich ECM proteoglycan, is able to prevent collagen degradation through its interaction with collagen fibrils (48). Moreover, it has been demonstrated that decorin is increased in tissue from patients with uncontrolled asthma; tissues from these patients present morphological changes similar to those described in the present chronic model animals (49). Despite the probable inaccessibility of interstitial collagens to the tissues studied, collagenase activity levels were maintained, possibly due to the increase in MMP-1 levels. Its synthesis may have been stimulated by the increase of some ECM components such as collagen type I and tenascin-C (28). MMP-1 participation in airway remodeling appears to be more relevant than MMP-13 in the chronic experimental model as well. It has been reported that MMP-1 expression is increased in airway epithelial cells, inflammatory cells and particularly ASM cells from asthmatic patients $(25,27,28)$. In this context, epithelial and ASM hyperplasia may be responsible for the MMP-1 expression increase in our experimental asthma model. In addition, the total collagenase activity observed in the 3 groups from the chronic model likely corresponds to MMP-1 and MMP-13 together with MMP-8, a collagenase that has also been identified in asthmatic patients $(50,51)$. Further research under identical experimental conditions is required to corroborate the MMP- 8 participation in interstitial collagen turnover in these experimental models of asthma. Nevertheless, the important role that MMP-1 has in ECM metabolism during airway remodeling is evident. It has been reported that MMP-1 protein concentration was increased in the outer wall of the small airways of patients with fatal asthma (27). Furthermore, it has been observed that MMP-1 mRNA transcripts are also increased in sputum cells from asthmatic patients with decreased $\mathrm{FEV}_{1}$ values (52). These data suggest that an increase in MMP-1 expression is a bad prognosis for this disease, although according to the results of the present study, its collagenase activity is not enough to prevent collagen deposition. It is evident that the molecular mechanism underlying the regulation of interstitial MMP synthesis and activation may also be altered.

Finally, chronic exposure to an allergen may irreversibly affect the molecular mechanisms underlying collagen synthesis and degradation. These structural changes that provoke airway wall thickening are responsible for the persistence and severity of bronchial obstruction in the asthmatic patient and in experimental asthmatic animals. Therefore, it is conceivable that the use of a drug that impairs interstitial collagen synthesis and increases its degradation administrated together with conventional therapy would benefit chronic severe asthma patients.

\section{References}

1. Bousquet J, Jeffery PK, Busse WW, Johnson M and Vignola AM: Asthma. From bronchoconstriction to airways inflammation and remodeling. Am J Respir Crit Care Med 161: 1720-1745, 2000.

2. Lemanske RF Jr and Busse WW: Asthma: Clinical expression and molecular mechanisms. J Allergy Clin Immunol 125 (2 Suppl 2): S95-S102, 2010

3. Murphy DM and O'Byrne PM: Recent advances in the pathophysiology of asthma. Chest 137: 1417-1426, 2010.
4. Lommatzsch M and Stoll P: Novel strategies for the treatment of asthma. Allergo J Int 25: 11-17, 2016.

5. Yamauchi $\mathrm{K}$ and Inoue $\mathrm{H}$ : Airway remodeling in asthma and irreversible airflow limitation-ECM deposition in airway and possible therapy for remodeling. Allergol Int 56: 321-329, 2007.

6. Chae EJ, Kim TB, Cho YS, Park CS, Seo JB, Kim N and Moon HB: Airway measurement for airway remodeling defined by post-bronchodilator FEV1/FVC in asthma: Investigation using inspiration-expiration computed tomography. Allergy Asthma Immunol Res 3: 111-117, 2011.

7. Aysola RS, Hoffman EA, Gierada D, Wenzel S, Cook-Granroth J, Tarsi J, Zheng J, Schechtman KB, Ramkumar TP, Cochran R, et al: Airway remodeling measured by multidetector $\mathrm{CT}$ is increased in severe asthma and correlates with pathology. Chest 134: 1183-1191, 2008.

8. Kaminska M, Foley S, Maghni K, Storness-Bliss C, Coxson H, Ghezzo H, Lemière C, Olivenstein R, Ernst P, Hamid Q and Martin J: Airway remodeling in subjects with severe asthma with or without chronic persistent airflow obstruction. J Allergy Clin Immunol 124: 45-51 e1-e4, 2009.

9. Orihara K, Dil N, Anaparti V and Moqbel R: What's new in asthma pathophysiology and immunopathology? Expert Rev Respir Med 4: 605-629, 2010

10. Chiappara G, Gagliardo R, Siena A, Bonsignore MR, Bousquet J, Bonsignore $\mathrm{G}$ and Vignola AM: Aiway remodeling in the pathogenesis of asthma. Curr Opin Allergy Clin Immunol 1: 85-93, 2001.

11. Hamid Q: Pathogenesis of small airways in asthma. Respiration 84: 4-11, 2012.

12. Kudo M, Ishigatsubo Y and Aoki I: Pathology of asthma. Front Microbiol 4: 263, 2013.

13. Tagaya E and Tamaoki J: Mechanisms of airway remodeling in asthma. Allergol Int 56: 331-340, 2007.

14. Murphy G and Nagase H: Progress in matrix metalloproteinases research. Mol Aspects Med 29: 290-308, 2008.

15. Tallant C, Marrero A and Gomis-Rüth FX: Matrix metalloproteinases: Fold and function of their catalytic domains. Biochim Biophys Acta 1803: 20-28, 2010.

16. Löffek S, Schilling O and Franzke CW: Series 'matrix metalloproteinases in lung health and disease': Biological role of matrix metalloproteinases: A critical balance. Eur Respir J 38: 191-208, 2011.

17. Brew $\mathrm{K}$ and Nagase $\mathrm{H}$ : The tissue inhibitors of metalloproteinases (TIMPs): An ancient family with structural and functional diversity. Biochim Biophys Acta 1803: 55-71, 2010.

18. Bergers G, Brekken R, McMahon G, Vu TH, Itoh T, Tamaki K, Thorpe P, Itohara S, Werb Z and Hanahan D: Matrix metalloproteinase-9 triggers the angiogenic switch during carcinogenesis. Nat Cell Biol 2: 737-744, 2000.

19. Greenlee KJ, Werb Z and Kheraddmand F: Matrix metalloproteinases in lung: Multiple, multifarious, and multifaceted. Physiol Rev 87: 69-98, 2007

20. Suzuki R, Miyazaki Y, Takagi K, Torii K and Taniguchi H: Matrix metalloproteinases in the pathogenesis of asthma and COPD: Implications for therapy. Treat Respir Med 3: 17-27, 2004.

21. Gueders MM, Foidart JM, Noel A and Cataldo DD: Matrix metalloproteinases (MMPs) and tissue inhibitors of MMPs in the respiratory tract: Potential implications in asthma and other lung diseases. Eur J Pharmacol 533: 133-144, 2006.

22. Vermeer PD, Denker J, Estin M, Moninger TO, Keshavjee S, Karp P, Kline JN and Zabner J: MMP9 modulates tight junction integrity and cell viability in human airway epithelia. Am J Physiol Lung Cell Mol Physiol 296: L751-L762, 2009.

23. Hoshino M, Nakamura Y, Sim J, Shimojo J and Isogai S: Bronchial subepithelial fibrosis and expression of matrix metalloproteinase-9 in asthmatic airway inflammation. J Allergy Clin Immunol 102: 783-788, 1998

24. Kumagai K, Ohno I, Imai K, Nawata J, Hayashi K, Okada S, Senoo H, Hattori T and Shirato K: The involvement of matrix metalloproteinases in basement membrane injury in a murine model of acute allergic airway inflammation. Clin Exp Allergy 32: 1527-1534, 2002.

25. Rajah R, Nachajon RV, Collins MH, Hakonarson $H$, Grunstein MM and Cohen P: Elevated levels of the IGF-binding protein protease MMP-1 in asthmatic airway smooth muscle. Am J Respir Cell Mol Biol 20: 199-208, 1999.

26. Huang CD, Lin SM, Chang PJ, Liu WT, Wang CH, Liu CY, Lin HC, Hsieh LL and Kuo HP: Matrix metalloproteinase-1 polymorphism is associated with persistent airway obstruction in asthma in the Taiwanese population. J Asthma 46: 41-46, 2009. 
27. Dolhnikoff M, de Silva LF, de Araujo BB, Gomes HA, Fernezlian S, Mulder A, Lindeman JH and Mauad T: The outer wall of small airways is a major site of remodeling in fatal asthma. J Allergy Clin Immunol 123: 1090-1097, 2009.

28. Rogers NK, Clements D, Dongre A, Harrison TW, Shaw D and Johnson SR: Extra-cellular matrix proteins induce matrix metalloproteinase-1 (MMP-1) activity and increase airway smooth muscle contraction in asthma. PLoS One 9: e90565, 2014.

29. Sommer B, Montaño LM, Chávez J, Gustin P and Vargas MH: Guinea pig lung resistance shows circadian rhythmicity not influenced by ozone. Respir Physiol 113: 223-229, 1998.

30. Hamelmann E, Schwarze J, Takeda K, Oshiba A, Larsen GL, Irvin CG and Gelfand EW: Noninvasive measurement of airway responsiveness in allergic mice using barometric plethysmography. Am J Respir Crit Care Med 156: 766-775, 1997.

31. Bazán-Perkins B, Vargas MH, Sánchez-Guerrero E, Chávez J and Montaño LM: Spontaneous changes in guinea-pig respiratory pattern during barometric plethysmogrphy: Role of catecholamines and nitric oxide. Exp Physiol 89: 623-628, 2004.

32. Sommer B, Vargas MH, Chavez J, Carbajal V, Segura P and Montaño LM: Differences between inhaled and intravenous bronchial challenge to detect $\mathrm{O}$ (3)-induced hyperresponsiveness J Appl Physiol (1985) 91: 2595-2601, 2001.

33. Bazán-Perkins B, Sánchez-Guerrero E, Vargas $M H$, Matinez-Cordero E, Ramos-Ramirez P, Alvarez-Santos M, Hiriart G, Gaxiola M and Hernández-Pando R: Betal-integrins shedding in a guinea-pig model of chronic asthma with remodeled airways. Clin Exp Allergy 39: 740-751, 2009.

34. Rojkind M and González E: An improved method for determining specific radioactivities of proline $14 \mathrm{C}$ and hydroxyproline-14C in collagen and in noncollagenous proteins. Anal Biochem 57: 1-7, 1974.

35. Smith PK, Krohn RI, Hermanson GT, Mallia AK, Gartner FH, Provenzano MD, Fujimoto EK, Goeke NM, Olson BJ and Klenk DC: Measurement of protein using bicinchoninic acid. Anal Biochem 150: 76-85, 1985.

36. Terato K, Nagai Y, Kawanishi $\mathrm{K}$ and Yamamoto S: A rapid assay method of collagenase activity using 14C-labeled soluble collagen as substrate. Biochim Biophys Acta 445: 753-762, 1976.

37. Gomez DE, Alonso DF, Yoshiji $\mathrm{H}$ and Thorgeirsson UP: Tissue inhibitors of metalloproteinases: Structure, regulation and biologic functions. Eur J Cell Biol 74: 111-122, 1997.

38. Nakashima AS, Prado CM, Lanças T, Ruiz VC, Kasahara DI, Leick-Malconado EA, Dolhnikoff M, Martins MA and Tibério IF: Oral tolerance attenuates changes in in vitro lung tissue mechanics and extracellular matrix remodeling induced by chronic allergic inflammation in guinea pigs. J Appl Physiol (1985) 104: 1778-1785, 2008
39. Dekkers BG, Bos IS, Gosens R, Halayko AJ, Zaagsma J and Meurs H: The integrin-blocking peptide RGDS inhibits airway smooth muscle remodeling in a guinea pig model of allergic asthma. Am J Respir Crit Care Med 181: 556-565, 2010.

40. Benayoun L, Druilhe A, Dombret MC, Aubier M and Pretolani M: Airway structural alterations selectively associated with severe asthma. Am J Respir Crit Care Med 167: 1360-1368, 2003.

41. Liesker JJ, Ten Hacken NH, Zeinstra-Smith M, Rutgers SR, Postma DS and Timens W: Reticular basement membrane in asthma and COPD: Similar thickness, yet different composition. Int J Chron Obstruct Pulmon Dis 4: 127-135, 2009.

42. Jeffery PK: Remodeling in asthma and chronic obstructive lung disease. Am J Respir Crit Care Med 164: S28-S38, 2001.

43. Saglani S, Molyneux C, Gong H, Rogers A, Malmström K, Pelkonen A, Mäkelä M, Adelroth E, Bush A, Payne DN and Jefferey PK: Ultrastructure of the reticular basement membrane in asthmatic adults, children and infants. Eur Respir J 28: 505-512, 2006.

44. Araujo BB, Dolhnikoff M, Silva LF, Elliot J, Linderman JH, Ferreira DS, Mulder A, Gomes HA, Fernezlian SM, James A and Mauad T: Extracellular matrix components and regulators in the airway smooth muscle in asthma. Eur Respir J 32: 61-69, 2008.

45. Woessner JF and Nagase $\mathrm{H}$ : Activation of the zymogen forms of MMPs.In Woessner JF, Nagase H (eds): Matrix Metalloproteinase and TIMPs. New York, Oxford University Press, 72-76, 2000.

46. Souza FC, Gobbato NB, Maciel RG, Prado CM, Martins MA, Leick EA and Tibério IF: Effects of corticosteroid, montelukast and iNOS inhibition on distal lung with chronic inflammation. Respir Physiol Neurobiol 185: 435-445, 2013.

47. Grzela K, Litwinluk M, Zagorska W and Grzela T: Airway remodeling in chronic obstructive pulmonary disease and asthma: The role of matrix metalloprotease-9. Arch Immunol Ther Exp (Warsz) 64: 47-55, 2016.

48. Geng Y, McQuillan D and Roughley PJ: SLRP interaction can protect collagen fibrils from cleavage by collagenases. Matrix Biol 25: 484-491, 2006.

49. Weitoft M, Andersson C, Andersson Sjöland A, Tufvesson E, Bjermer L, Erefält J and Westergren-Thorsson G: Controlled and uncontrolled asthma display distict alveolar tissue matrix compositions. Respir Res 15: 67, 2014.

50. Kerrigan JJ, Mansell JP and Sandy JR: Matrix turnover. J Orthod 27: 227-233, 2000.

51. Prikk K, Maisi P, Pirilä E, Reintam MA, Salo T, Sorsa T and Sepper R: Airway obstruction correlates with collagenase-2 (MMP-8) expression and activation in bronchial asthma. Lab Invest 82: 1535-1545, 2002.

52. Cataldo DD, Gueders M, Munaui C, Rocks N, Bartsch P, Foidart JM, Noël A and Louis R: Matrix metalloproteinases and tissue inhibitors of matrix metalloproteinases mRNA transcripts in the bronchial secretions of asthmatics. Lab Invest 84: 418-424, 2004. 